ORIGINAL ARTICLE

\title{
Dental Anxiety Measurement of Children in Abbottabad Using Audio Visual System
}

\author{
TALIB HUSSAIN ${ }^{1}$, SIKANDAR JAVED BAJWA², SALVAN GHANI ${ }^{3}$, BEENISH ALAM ${ }^{4}$, MALIK ARSHMAN KHAN ${ }^{5}$, ADIL \\ DURRANI ${ }^{6}$ \\ ${ }^{1}$ Associate Professor Oral Biology, Women Medical \& dental college, Abbottabad \\ ${ }^{2}$ Associate Professor Oral Biology, Lahore Medical \& Dental College, Lahore \\ ${ }^{3}$ Assistant Professor Oral Biology, Women Medical \& dental college, Abbottabad \\ ${ }^{4}$ Assistant Professor Oral Biology, Bahria University Medical \& Dental College \\ ${ }^{5}$ Associate Professor Oral Biology, Abbottabad International Medical \& Dental College \\ ${ }^{6}$ Associate Professor Oral Biology, Foundation University College Of Dentistry Islamabad \\ Correspondence to Dr Sikandar Javed Bajwa Email sikandar.bajwa15@gmail.com Cell: 03334761848
}

\begin{abstract}
Aim: To measure the anxiety and fear in children while visiting dentist and to observe effectiveness of audiovisual assistance to overcome anxiety

Study design: Qualitative study

Place and duration of study the study is done in Rehmat Memorial Hospital Abbottabad department of operative dentistry, affiliated with Women Medical and Dental College Abbottabad, from December 2014 to February 2017.

Methods: Total two hundred children were observed aged between 5-8 years at Rehmat Memorial Hospital Abbottabad under controlled conditions showing cartoons on TV screen by using wireless headphones. There were two main groups divided into the controlled group and uncontrolled group containing one hundred participants in each group. Each patient's pulse rate, heart rate was recorded and live pulse rate was in sight by using wristband with pulse rate detector. Venham's picture test was used to check the correct reaction of the patient for the assessment of degree of anxiety more realistically.

Results Controlled group $n=100$ and uncontrolled group $n=100$ patient aged $5-8$ years treated for various procedures in different appointments. With mean age 6-7 years, Male to female ration of participants in controlled group was $34 \%$ and $66 \%$ and in uncontrolled group male and female ration was $45 \%$ and $55 \%$. Significant reduction in anxiety was noted in controlled group distracted by audio visual stories and rhymes.

Conclusion: Both groups were statistically evaluated and the result showed that audiovisual distraction can decrease the anxiety level in the controlled group but couldn't eliminate completely. This issue needs more studies and experiments to resolve anxiety in children completely.

Keywords: Dental anxiety, Venham's picture test, child behaviour
\end{abstract}

\section{INTRODUCTION}

Oral hygiene is an imperative part of the overall health of children. The prevalent explanation for children to escape visiting the dentist was suffering from pain phobia from several years ago now ${ }^{1}$. The functional, psychological and social aspects of a child's everyday life have a colossal impact on children's oral health. Oral pain affects children with troubling results, including insomnia, poor body growth, issues with attitude and disrupted learning ${ }^{2}$.

In children with dental anxiety and fear, efficacious and skilled dental treatment cannot be achieved. A dentist who treats children should have miscellaneous experience and behaviour guidance approaches. Different children have different kinds of stages of growth that influence their dental attitude and disposition levels. Dentists should be able to assess and forecast the child's response to therapy (Guideline on Paediatric Dental Patient).

When treating an uncooperative child patient due to anxiety, the term dental fear is used synonymously for dental anxiety ${ }^{3,4}$. It's common knowledge that fear of pain results in unwillingness to appropriate treatment ${ }^{5}$. These complications at times urge the dentist to employ more complex procedures, such as sedation or general

Received on 26-01-2021

Accepted on 27-05-2021 anaesthesia. Several sources say that $5 \%^{6}$ to $52 \%{ }^{7}$ of the children show extreme concern or distress in regards to getting dental work undertaken.

More comprehensive studies have shown that apprehension of pain is generally found more in girls as dental anxiety is associated with overall fear ${ }^{1}$. Fear has been shown to be strongly linked to the fear of pain, as shown in previous studies. Because of that, oral health issues may arise due to a spike in fear, anxiety and nervousness ${ }^{2}$. McCaul and Mallet put the idea forward, hypothesizing that the attentional potential of humans had a capacity limit. As a result, when a person's attention is elsewhere, and diverted from treatment, the feeling of pain is diminished ${ }^{8}$.

First and foremost, the apprehension must be calculated in order to relieve anxiety. A technique for testing fear in children may be both pleasurable and unpleasant. Questionnaire-based assessments help to alleviate fear to some extent because they depend heavily on other observers and the child's reactions. Tactics that concentrate on particular forms of verbal-cognitive selfreporting, on the other hand (e.g. questionnaires). While it is comparatively easy to ask children specifically about dental anxiety, verbal approaches used for young children can be constrained by their comprehension and intellectual ability ${ }^{9}$. 
The optimal assessment must have modest cognitive and linguistic capabilities; it must be valid; it must be capable of being administered and evaluated in a therapeutic setting. The most natural choice would be to use a scale that has a complete range of values for all these parameters. The only image scale that is available is the Venham picture test (VPT) ${ }^{10}$ used to assess anxiety in a range of experiments ${ }^{11,12,13}$. Eight similar images representing seven opposite feelings are given to the children in this project. You will have to go for the one that is now exciting you the most at the moment. The benefit of this policy is that it is simple to apply and maintain. It has been demonstrated to be valid but subject to some restrictions. If the young person is a girl, it could be difficult to recall the card numbers because boy cartoons are male. However, it should be noted that certain forecasts fall short of actual results. Finally, the scale is lengthy, which may pose a significant obstacle to patients under the age of 10 years old ${ }^{11,12}$.

The objective of the study was to measure the anxiety and fear in children while visiting dentist and to observe effectiveness of audiovisual assistance to overcome anxiety,

\section{MATERIAL AND METHOD}

The controlled group was monitored by using venham's picture test and their live pulse rate was monitored during treatment. Under controlled conditions, patients were shown cartoon or poems as per choice of patient on LCD monitor in front of the dental chair and cartoon's voice was transmitted to the patient by using wireless Bluetooth headphones. By this way, the patient couldn't hear handpiece noise and attention is diverted towards poems or cartoons instead of procedure. Using pulse rate and venham's picture chart data was recorded. The research was carried out in the Department of Peadodontics and Preventive Dentistry at Rehmat Memorial Hospital in Abbottabad affiliated with Women Medical and Dental College Abbottabad after permission from Ethical Committee. The research enlisted the participation of 200 children aged 5-8.

Inclusion criteria: Both groups patients were medically and mentally well and had attended a dental clinic but refused care.

Exclusion criteria: Patients with their first appointment and some form of abnormality is ruled out of the sample.

Group 1: includes 100 patient under controlled conditions

Group 2: includes 100 children under uncontrolled conditions.

During therapy, the controlled group was monitored using Venham's Picture Test (VPT) and their live pulse rate was tracked. Patients were shown cartoons or poems, animated movies, on LCD display in front of the dental chair, and the voice of the cartoon was transmitted to the patient via wireless Bluetooth headphones, under monitored conditions. As a result, the patient is oblivious to handpiece noise, and his or her attention is drawn to poetry or cartoons rather than the treatment. The data was collected using the heart rate and the Venham's image table.

Venham's Picture test (VPT)
- Assessment is simple and requires no specialized ability.

- $\quad$ The Venham Image Test (VPT) (Figure. 1) contains 8 cards, each of two numbers, one figure of "anxiety," and one figure, one figure of "non anxiety." The children were asked to show the number they thought most at the time.

- In its numbered order, all cards were shown. If the child indicated the 'fearful' statistic a score of one was registered, then a zero was reported if the child indicated the 'non-fearful' number. The number of times you have selected the 'anxious' number has been added to a final result (minimum score, zero; maximum score, eight) ${ }^{14}$.

Each card has two faces, one happy and the other sad, depending on the reaction. Aside from that, the uncontrolled group was handled normally, with no audiovisual distractions.

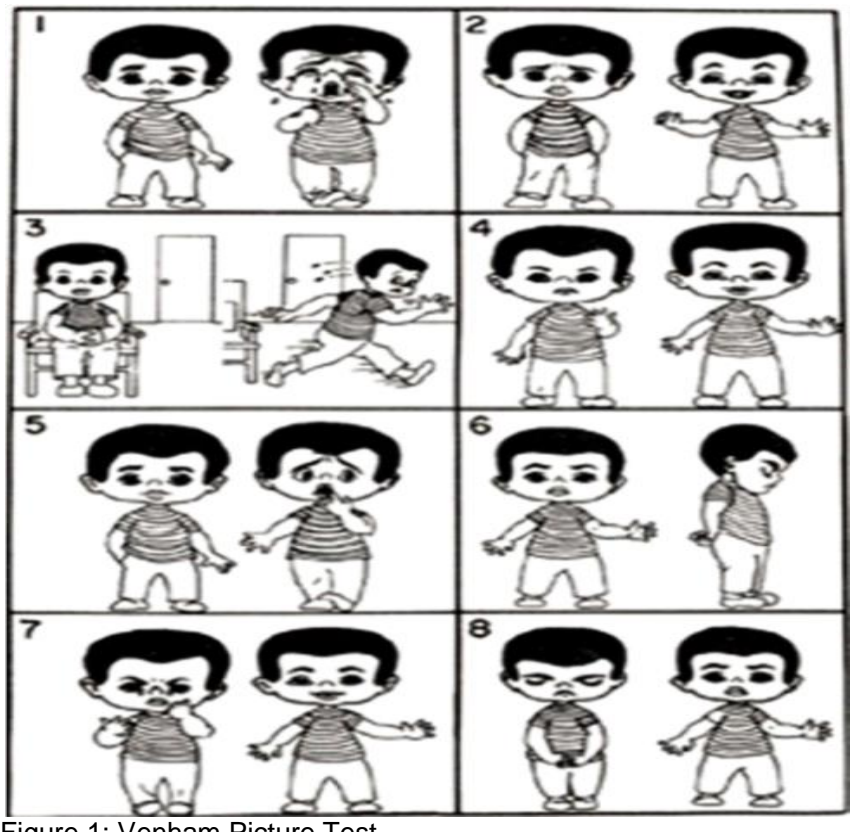

Figure 1: Venham Picture Test

\section{RESULTS}

Total 200 children participated in this study. Majority of patients were boys compare to girls. Mean age was 6.7 years. Male to female ration of participants in controlled group was $34 \%$ and $66 \%$ respectively. In uncontrolled group male were $45 \%$ while female was $55 \%$.

Table 1: Readings from controlled group

Table 1: Readings from controlled group
\begin{tabular}{|l|l|}
\hline Venham Picture Score & No. of Children \\
\hline 0 & 8 \\
\hline 1 & 12 \\
\hline 2 & 15 \\
\hline 3 & 19 \\
\hline 4 & 20 \\
\hline 5 & 16 \\
\hline 6 & 4 \\
\hline 7 & 4 \\
\hline 8 & 2 \\
\hline
\end{tabular}


Data from VPT analysis for controlled and uncontrolled group shown in Table 1 and Table 2 respectively. Mean value and standard deviation were calculated by using these values shown in Table 3 . The two tail $Z$ test was applied to determine whether the significance between two groups. Since it was observed that $z=1.04$ and $p$-value 0.029 . As a result, statistically relationship was discovered between the controlled group and uncontrolled group. Results showed significant difference in anxiety for controlled and uncontrolled group.

Table 2: Reading from uncontrolled group

\begin{tabular}{|l|l|}
\hline Venham Picture Score & No. of Children \\
\hline 0 & 20 \\
\hline 1 & 11 \\
\hline 2 & 15 \\
\hline 3 & 14 \\
\hline 4 & 11 \\
\hline 5 & 12 \\
\hline 6 & 11 \\
\hline 7 & 5 \\
\hline 8 & 1 \\
\hline
\end{tabular}

Table 3: Mean Venham picture scale scores in Group I \& Group II

\begin{tabular}{|l|l|l|l|}
\hline Groups & n & St. Deviation SD & Mean \\
\hline controlled group & 100 & 1.96 & 3.27 \\
\hline uncontrolled group & 100 & 2.24 & 2.96 \\
\hline
\end{tabular}

\section{DISCUSSION}

Dental fear within children can have numerous reasons and causes. Children's prior familiarity and attitude regarding dentistry as well as children's nature and their behaviour all play a key role in determining a child's anxiety level ${ }^{16}$.

A positive correlation has been noted between maternal anxiety and child's perception regarding dentistry. Children who receive stressful information regarding parent's dental appointments are more likely to develop a similar attitude towards dentistry, resulting in having anxious behavior ${ }^{17}$. This negative behaviour plays a vital role in fear elicitation, creating the person nervous and difficult to treat, hence making them less accommodating with anxiety handling methods ${ }^{18}$. These highly apprehensive patient not only present having negative thoughts, and a sturdier effort is needed to control this thought pattern near to the time of the dental appointment 19. Moreover, a study conducted by Peretz and Mann stated that the level of dental anxiety was significantly higher for children who had past experience with dentistry, while those children who had no prior experience of anxiety or dental visit had comparatively lower scores ${ }^{20}$. Likewise, similar studies conducted by Colares et al. Nicolas et al and Soares et al have suggested that patients who have never visited the dentist are more likely to have an anxious attitude towards dentistry. Additionally, it was reported by Howitt and Stricker that children's approach improves towards dental treatments by incorporation of increased dental visits ${ }^{21}$.

Further research carried out by Koenigsberg and Johnson stated that no association has been noted between anxiety and consecutive dental visits ${ }^{22}$. A survey conducted by Peretz et al. revealed that phase of life, schooling, place of birth, along with prior dental management does not have a substantial impact upon the
Dental Anxiety Scores (DAS) of children. Similarly, the current study has demonstrated that earlier dental experience does not have a significant impact upon the Venham Picture Scale scores conducted on school going children and the results are in accord with the previously conducted research. It can be attributed to the proficient interpersonal expertise of the dental professional along with demonstrating motivational and awareness education regarding dentistry, improved health educational programs conducted in schools and increased awareness of dentistry through media coverage. Moreover, due to advances in technical industry with the development of the latest products of improved quality, such as with advances in local anaesthesia and with the introduction of the latest treatment strategies, it has significantly improved the dental experience of many nervous patients ${ }^{20}$.

The results of the current study revealed that most of the children surveyed had considerably reduced levels of anxiety; though, few children significantly displayed higher level of dental fear. It can be attributed to having fright of having teeth being taken out and possibly due to fear of needles.

A few limitations that can be highlighted from the current study are the limited sample size of the study and being a single centre based study. Therefore, it is recommended that multi-centric research be conducted including the different schools for better results to be generated to understand the factors responsible for causing dental anxiety among children.

\section{CONCLUSION}

It has been recognized that modern, simpler, and more efficient behaviour management approaches are needed. In the case of paediatric dentistry, the diversion strategy is one such revolutionary option for coping with a child's dental anxiety. To recap, the audio-visual distraction approach outperformed audio distraction alone in handling nervous children in the dental clinic.

The research yielded a variety of findings. Throughout all of the dental operations, dental anxiety was a normal occurrence. When compared to children handled in a traditional setting, stories, songs, and nursery rhymes were substantially more effective in reducing anxiety. Audiostories diversion was the most successful of these. A trend of increased anxiety in the children was found across both groups and as the magnitude and invasiveness of the dental operating procedures increased, though to a lesser extent in the audio distraction community, especially in the audio stories group, as opposed to the control group.

Acknowledgement: We acknowledge the Department of Pedodontics and Preventive Dentistry Rehmat Memorial Dental Hospital affiliated with Women Medical and Dental College Abbottabad for their assistance and support. We would also like to express our gratitude to the children and parents who took part in the research.

Conflict of interest: Nil

\section{REFERENCES}

1. Fazli M, Kavandi MR, Malekafzali B. A Method Towards Children's Psychological Health on Dental Visits. ProcediaSocial and Behavioral Sciences. 2014 Feb 21;114:420-6. 
2. Salem K, Kousha M, Anissian A, Shahabi A. Dental fear and concomitant factors in 3-6 year-old children. Journal of dental research, dental clinics, dental prospects. 2012;6(2):7

3. Gustafsson A. Dental behaviour management problems among children and adolescents-a matter of understanding? Studies on dental fear, personal characteristics and psychosocial concomitants. 2010 Jan 26.

4. Gustafsson, A., Arnrup, K., Broberg, A.G., Bodin, L., \&Berggren, U.( 2007). Psychosocial concomitants to dental fear and behaviour management problems. Int $\mathrm{J}$ Paediatr Dent, , 17,449-459.

5. Al-Khotani A, Bello LA, Christidis N. Effects of audiovisual distraction on children's behaviour during dental treatment: a randomized controlled clinical trial. Acta Odontologica Scandinavica. 2016;74(6):494-501.

6. Bankole OO, Aderinokun GA, Denloye OO, et al. Maternal and child's anxiety - effect on child's behaviour at dental appointments and treatments. Afr $\mathrm{J}$ Med Med Sci. 2002;31:349-352.

7. Folayan MO, Fatusi A. Effect of psychological management techniques on specific item score change during the management of dental fear in children. J Clin Pediatr Dent. 2005;29:335-340.

8. Jackson SL, Vann WF J r, KotchJB Pahel B T, Lee J Y. Impact of poor oral healthon children's school attendance and performanceAm J Public Health 2011; 101(10):1900-6.

9. Zachariasen RD, Dennison DK. Periodontal disease and preterm low birth weight deliveries. J Gt Houst Dent Soc 1998;70(4):16-9

10. Dasanayake A P. Poor periodontal health of the pregnant woman as a risk factor for low birth weight. Ann Periodontal 1998;3(1):206-12.

11. Clarke M, Locker D, Berall G, Pencharz P, Kenny DJ, Judd P . Malnourishment in a population of young childrenwith severe early Childhood caries.Pediatr Dent 2006;28(3):254-9.

12. Locker D, Matear D; Community Health Services Research Unit, Faculty of Dentistry, University of Toronto. Oral disorders, systemic health, well-being and the quality of life A summary of recent researchevidence.2000. www.utoronto.ca/dentistry/ facultyresearch/dri/cdhsru/health_measurement/7.\%20\%20N 0\%2017.pdf (Accessed November 26, 2012).

13. Aartman IHA, Van Everdingen TA, Hoogstraten J, Schuurs AHB. Self-report measurements of dental anxiety and fear in children: a critical assessment. 1998; 65 Journal of Dentistry for Children: 252-258.
14. Alwin NP, Murray JJ, Britton PG. An assessment of dental anxiety in children. British Dental Journal 1991: 201-207.

15. Venham LL. The effect of mother's presence on child's response to dental treatment. Journal of Dentistry for Children 1979; 46: 219-225.

16. Alwin NP, Murray JJ, Niven N. The effect of children's dental anxiety on the behaviour of a dentist. International Journal of Paediatric Dentistry 1994; 4: 19-24

17. Klorman R, Ratner J, Arata CLG, King JB, Sveen OB. Predicting the child's uncooperativeness in dental treatment from maternal trait, state, and dental anxiety. Journal of Dentistry for Children 1978; 45: 62-67.

18. Kroniṇa L, Rasčevska M, Care R. Psychosocial factors correlated with children's dental anxiety. Stomatologija. 2017;19(3):84-90.

19. AIA Sm Ari AA, Aldo SS Ari GS, Mohammed S. Dental Anxiety in Children: A Review of the Contributing Factors. children. 2018 Apr 1;5:7.

20. Al-Namankany A, De Souza M, Ashley P. Evidence-based dentistry: analysis of dental anxiety scales for children. British dental journal. 2012 Mar;212(5):219.

21. Kent G, Gibbons R. Self-efficacy and the control of anxious cognitions. J Behav Ther Exp Psychiatry 1987; 18: 33-40.

22. Agarwal MD, Das UM. Dental anxiety prediction using Venham Picture test: A preliminary cross-sectional study. Journal of Indian Society of Pedodontics and Preventive Dentistry. 2013 Jan 1;31(1):22.

23. Howitt JW, Stricker G. Sequential changes in response to dental procedure. J Dent Res 1970;49:1074-7.

24. Koenigsberg SR, Johnson R. Child behavior during three dental visits. J Dent Child 1975;34:197-200.

25. Peretz B, Nazarian Y, Bimstien E. Dental anxiety in a student's pediatric dental clinic: Children, parents and students. Int J Pediatr Dent 2004;14:192-5.

26. McCaul, K.D.,\& Mallot, J.M. (1984). Distraction and coping with pain. Psychol Bull,95,516-533.

27. Klinberg G, Raadal M, Arnup K. Dental fear and behavior management problems. In: Koch G, Poulsen S, eds. Pediatric Dentistry: A Clinical Approach. Singapore: Wiley Blackwell Publishing; 2009.

28. Nakai $Y$, Hirakawa T, Milgrom $P$, Coolidge $T$, Heima M, Mori $Y$, et al. The children's Fear Survey Schedule-Dental Subscale in Japan. Comm Dent Oral Epidemiol 2005; 33:196204. 